\title{
Modelling the spatio-temporal interplay between North Sea saithe (Pollachius virens) and multiple fleet segments for management evaluation
}

\author{
Sarah Laura SIMONS ${ }^{1,2, a}$, Ralf DöRING ${ }^{1}$ and Axel TEMMING ${ }^{2}$ \\ 1 Johann Heinrich von Thünen Institute (Federal Research Institute for Rural Areas, Forestry and Fisheries), Institute of Sea Fisheries, \\ Palmaille 9, 22767 Hamburg, Germany \\ 2 Institut für Hydrobiologie und Fischereiwissenschaft, Universität Hamburg, Olbersweg 24, 22767 Hamburg, Germany
}

Received 31 December 2013; Accepted 18 June 2014

\begin{abstract}
There is growing interest in bio-economic models as tools for understanding pathways of fishery behaviour, in order to assess the impact on natural resources. Based on 'FishRent', a modelling approach is presented that integrates economics of the fleet, the impact of fishing on stock development and their spatio-temporal interplay. The simulation of species seasonal movements in combination with both observed values and stochastic recruitment allowed analysing the economic response of fleet segments to changes in stock distribution and development. Optimisation of net profits determines the effort adjustment and spatial allocation of fleet segments, which in turn affects the level of catch rates. Effort tended to concentrate where fish abundance was high, but also where fishing costs were low. In simulations with the current management plan spawning stock of North Sea saithe (Pollachius virens) declined below its precautionary reference point. In response fishing far from home ports became expensive and $40 \%$ of the initial effort was shifted to areas closer to home ports, but as areas of high fish concentrations were located by the modelled fleet segments catch rates remained high. Changes in seasonal/annual stock distribution, the stock decline and costs influenced the change in fishing effort distributions leading to overestimated catch per unit of effort values that masked the decline of stock abundance.
\end{abstract}

Keywords: Bio-economics / Fisheries economics / Fleet dynamics / Spatial structure / Stock assessment / Population dynamics

\section{Introduction}

Saithe (Pollachius virens) is of major economic importance for North Sea fisheries, with annual landings values of around 15 million euros (Anderson and Guillen 2009). It is targeted by Norwegian, French, German, British, Danish, and to a small extend Swedish trawlers (ICES 2013). There exists an EU-Norway long-term management plan for North Sea saithe. This plan involves a harvest control rule (HCR) based on annual total allowable catches (TACs), and reference points. $B_{\text {lim }}$ is a reference point for the spawning stock biomass (SSB), below which recruitment is impaired with a high probability (Lassen and Medley 2001; ICES 2013). $B_{\mathrm{pa}}$ is the precautionary reference point for SSB, below which the stock would be regarded as potentially overfished (Lassen and Medley 2001; ICES 2013). $F_{\text {tar }}$ is the average fishing mortality for age group 3-6 that is set as a target (Lassen and Medley 2001; ICES 2013). In the long-term management plan for North Sea saithe, $F_{\text {tar }}$ is set to $0.1\left(F_{\text {tar-low }}\right)$, when SSB is estimated to be below

a Corresponding author: sarah.simons@ti.bund.de the minimum level of $106000 \mathrm{t}\left(B_{\lim }\right)$ (ICES 2013). Usually the fishing mortality is around 0.4 , a $F_{\text {tar }}$ of 0.1 is therefore a strong reduction to allow SSB to recover. Where SSB is above $200000 \mathrm{t}\left(B_{\mathrm{pa}}\right)$, the parties agreed to restrict fishing on the basis of a TAC consistent with a target fishing mortality of 0.3 $\left(F_{\text {tar-up }}\right)$ (ICES 2013). In the case where SSB is estimated to be between $B_{\mathrm{pa}}$ and $B_{\text {lim }}$ the target fishing mortality rate $\left(F_{\text {tar-mid }}\right)$ is calculated as:

$$
F_{\text {tar-mid }}=F_{\text {tar-up }}-\left(F_{\text {tar-up }}-F_{\text {tar-low }}\right) \times \frac{\left(B_{\text {pa }}-S S B\right)}{\left(B_{p a}-B_{\text {lim }}\right)}
$$

Another element of the plan is that the annual TAC should not vary by more than $15 \%$ (ICES 2013). SSB estimates of saithe in the North Sea are based on age-based cohort models that are parameterised with data from surveys and commercial catches (ICES 2013). This analysis is conducted by working groups of the International Council for the Exploration of the Sea (ICES). Although, understanding and anticipating fishermen's response to changes in biological, economic, and regulatory conditions in fisheries is critical to designing 
management plans that will sustain both resources and fishing activities (Béné et al. 2001; Cambiè et al. 2012), the HCR on which ICES bases its advice is mainly based on biological considerations which exclude economic aspects and the spatio-temporal interaction between stocks and fleet segments (ICES 2013). Ideally these models would take into account the effects of short- and long-term fleet dynamics such as effort distribution and entry-exit behaviours, as they influence fishing mortality. Fleet dynamics are driven by revenues which in turn depend on fish prices and variable costs (such as fuel cost), and influences greatly the short-term effort distribution towards a fishery or another. In addition, the profit of a fleet segment will affect the investment or disinvestment behaviour and thus the long-term development of the targeted fish stocks.

Especially for species living in temperate zones such as saithe, different dispersal and movement patterns are seasonal and often tied to reproduction and feeding (Pelletier and Magal 1996). Fishermen take advantage of this behaviour and target the spawning or feeding concentrations (Pelletier and Magal 1996). Hilborn and Ledbetter (1979) was one of the first studies which showed that fishermen will move to areas where the catch rates are higher, and will generally shift their effort as catch rates change. The spatial heterogeneity in the dispersal of the resource will affect the spreading of fishing effort. In turn, the allocation of fishing effort may significantly alter the patterns of resource distribution. In order to understand the joint dynamics of both fish stock and fishermen, stock assessment should not ignore the effects of fleet dynamics on the stock development (Opaluch and Bockstael 1984; Hilborn 1985; Allen and McGlade 1986; Hilborn and Walters 1992; Booth 2000; Kerr et al. 2010). Fishing fleets develop and respond to regulations in order to maintain or enhance their income. Fishermen may alter fishing gears, expand into deeper waters (containing larger fish), start fishing in different areas, or target different components of the population (spawning aggregations vs. dispersed individuals) (Hilborn and Walters 1992). This in turn will have an impact on commercial stocks (e.g., Wilen 1979; Hilborn 1985; Hilborn and Walters 1992). Understanding the economic response of fleet segments to regulations is hence crucial for a sustainable management.

This study provides a tool that includes the economics of the fleet (e.g., fishing costs, fish and fuel prices, and fishermen behaviour), the dynamics of the stock (e.g., recruitment and SSB development) in relation to fisheries, and their spatio-temporal interplay. The approach is based on FishRent which is a bio-economic optimisation and simulation model (Salz et al. 2011). This model was extended by integrating an age-structured population model and the spatial dimension explicitly. The purpose of this research was to evaluate the current management plan under consideration of species seasonal movements, variable recruitment success and the economics of multiple fleet segments.

\section{Materials and methods}

\subsection{Settings}

The model was run for a period of 9 years (2007-2015). The model accounted for four fleet segments with North Sea saithe either as main target or important by-catch species, covering vessels from Denmark, England, France and Germany (see main home ports Fig. 1). According to the Data Collection Framework (DCF) fleet segments were classified by vessel length and predominant gear type (Commission Decision 2009). The North Sea and Skagerrak were subdivided by the grid of ICES rectangles $\left(30 \times 30\right.$ nautical mile $\left.{ }^{2}\right)($ Fig. 1). All ICES rectangles of the North Sea and Skagerrak were included in the model, but to highlight the main results a focus was laid on three zones, covering the spawning and partly the feeding grounds of North Sea saithe as well as the main fishing grounds of the modelled fleet segments (Fig. 1). The calibration of the biological module was based on average biological data from the current assessment and independent scientific survey data from the International Bottom Trawl Survey (IBTS) of the first quarter of the years 2005-2007 (ICES 2013). To calibrate the economic part of the model economic data for the period 2005-2007 were used (Anderson and Guillen 2009). Historical data was used in order to compare simulation results to actual observations.

\subsection{Scenarios}

For both scenarios the current long-term management plan for North Sea saithe was implemented and Total Allowable Catches (TACs) and target fishing mortality rates were modelled according to that plan (ICES 2013). For the baseline even scenario a homogenous distribution of the resource over all ICES rectangles without any movement was assumed $\left(S_{\text {even }}\right)$. In this scenario, a decrease or increase in stock size had an equal effect on all areas. The $S_{\text {diverse }}$ scenario included species seasonal migrations to feeding and spawning grounds, dispersal of fish to adjacent areas and contraction of the stock in response to stock size. Although these simulations can only be a stylized representation of real movements, due to insufficient empirical information, there are several reasons why they should be considered in models that are used for management evaluations. First, they are useful to demonstrate the impacts of directional movements of fish to the resulting spatial patterns of effort allocation of fleet segments. Second, migration patterns influence the distance between the fishing grounds and ports of fleet segments, which through fuel use, investments and available time for fishing directly affect profits.

\subsubsection{Seasonal movements}

In the model, at the end of each monthly time step, fish movements are computed and the number of individuals in each age group in each area is adjusted according to

$$
\begin{aligned}
N_{t, i, a}= & N_{t-1, i, k}\left[1-\sum_{\forall l \neq k}\left(\operatorname{dis}_{k, l}+\operatorname{seas}_{k, l}\right)\right] \\
& +\sum_{\forall k \neq l} N_{t-1, i, l}\left(\operatorname{dis}_{l, k}+\operatorname{seas}_{l, k}\right)
\end{aligned}
$$

where $\operatorname{dis}_{k, l}$ and $\operatorname{seas}_{k, l}$ are the dispersal rate and the seasonal migration rate from ICES rectangle $k$ to contiguous ICES rectangle $l$, respectively. Hereby individuals can only move north, south, east or west. Dispersal of fish between contiguous ICES 


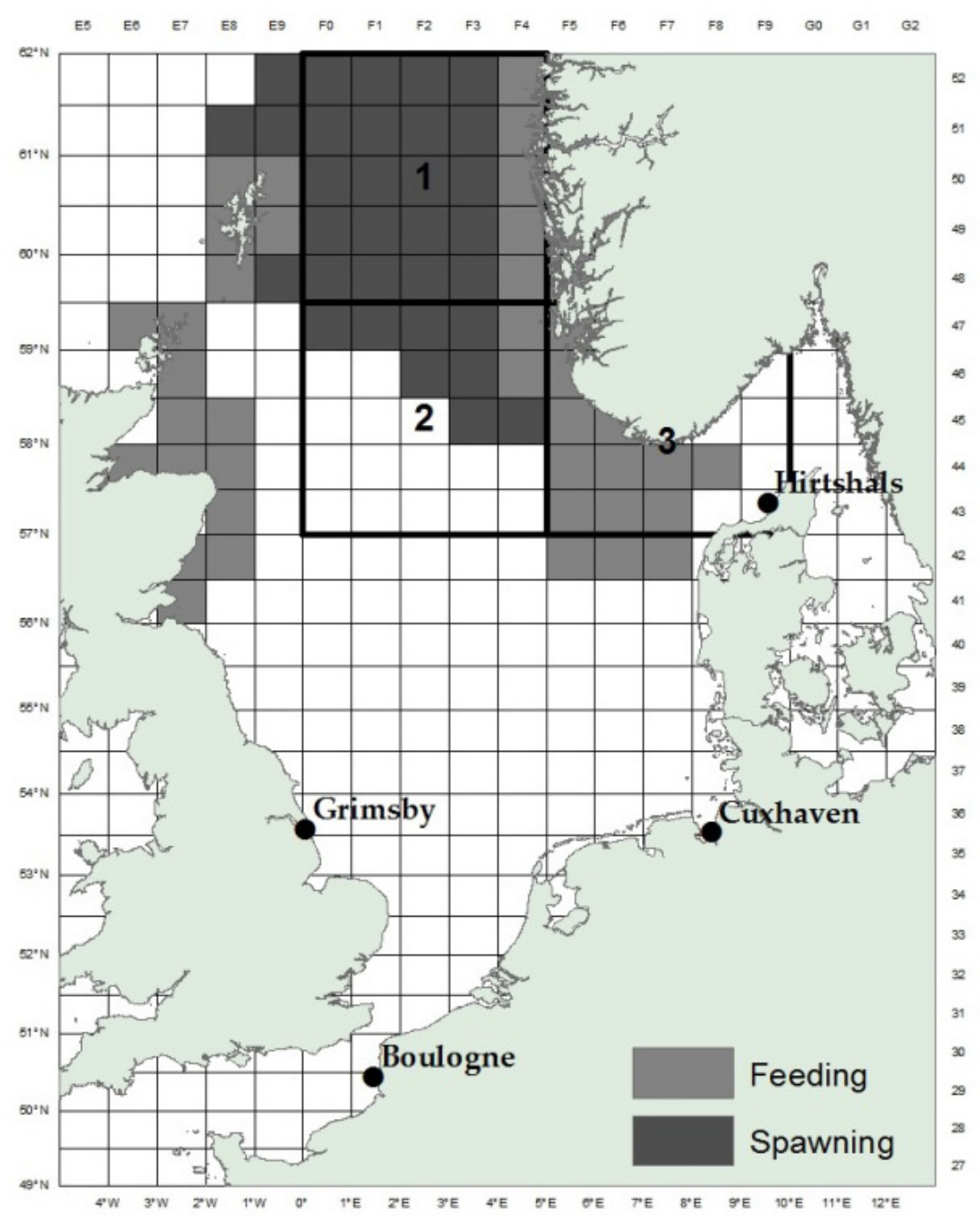

Fig. 1. The spatial layout for simulations of the North Sea saithe fishery. The North Sea is subdivided by the grid of ICES rectangles with a focus on three zones, covering partly the feeding grounds (grey) and the spawning ground (black) of North Sea saithe. Main home port for the Danish (Hirtshals), English (Grimsby), French (Boulogne) and German (Cuxhaven) fleet segment are shown.

rectangles was included, because little is known about the rate of movement of saithe. Dispersal rates were equal for each age group and were set to 0.005 . This implies that $0.5 \%$ of the fish population in each ICES rectangle is moved north, south, east, and west to each contiguous ICES rectangle each month. The seasonal migration rate allows a directional movement of fish in addition to the random component of movement modelled as dispersal. The migration parameter $\left(\operatorname{seas}_{k, l}\right)$ was set to 0.023 . This implies that each month $2.3 \%$ of fish in ICES rectangle $k$ is moved to one contiguous ICES rectangle lin addition to and independent of whatever movement occurs as a result of dispersal. The value for the movement parameters were set such that the density of the stock during the feeding and spawning period, respectively, approximates observed relative densities from scientific survey data of the International Bottom Trawl Survey (IBTS) for that stock during these times of the year (1st and 3rd quarter).

Based on different studies it is assumed in the model that juvenile saithe reside in inshore waters the first 2-3 years
(Bertelsen 1942; Reinsch 1976; Clay et al. 1989; Armannsson et al. 2007). In the model, recruits of age three are evenly distributed within the feeding grounds along the Norwegian coast (Fig. 1). As adults, saithe is assumed to move to offshore waters (Jones and Jonson 1971; Reinsch 1976; Homrum et al. 2012) and exhibit seasonal migrations between spawning and feeding areas (Jones and Jonson 1971; Olsen et al. 2010) (Fig. 1). From November to January the modelled individuals that are three years or older migrate from the feeding grounds to the spawning ground (Jones and Jonson 1971; Olsen et al. 2010), choosing the shortest way by moving north, south, west or east (Fig. 2). Spawning is assumed to occur in February and individuals stay on the spawning ground during this month (Fig. 2). From March to May modelled fish is assumed to migrate from the spawning ground to the feeding grounds (Jones and Jonson 1971; Olsen et al. 2010), choosing again the shortest way (Fig. 2). Individuals stay at the feeding grounds from June to October, before they anew migrate to the spawning ground between November and January (Fig. 2). 


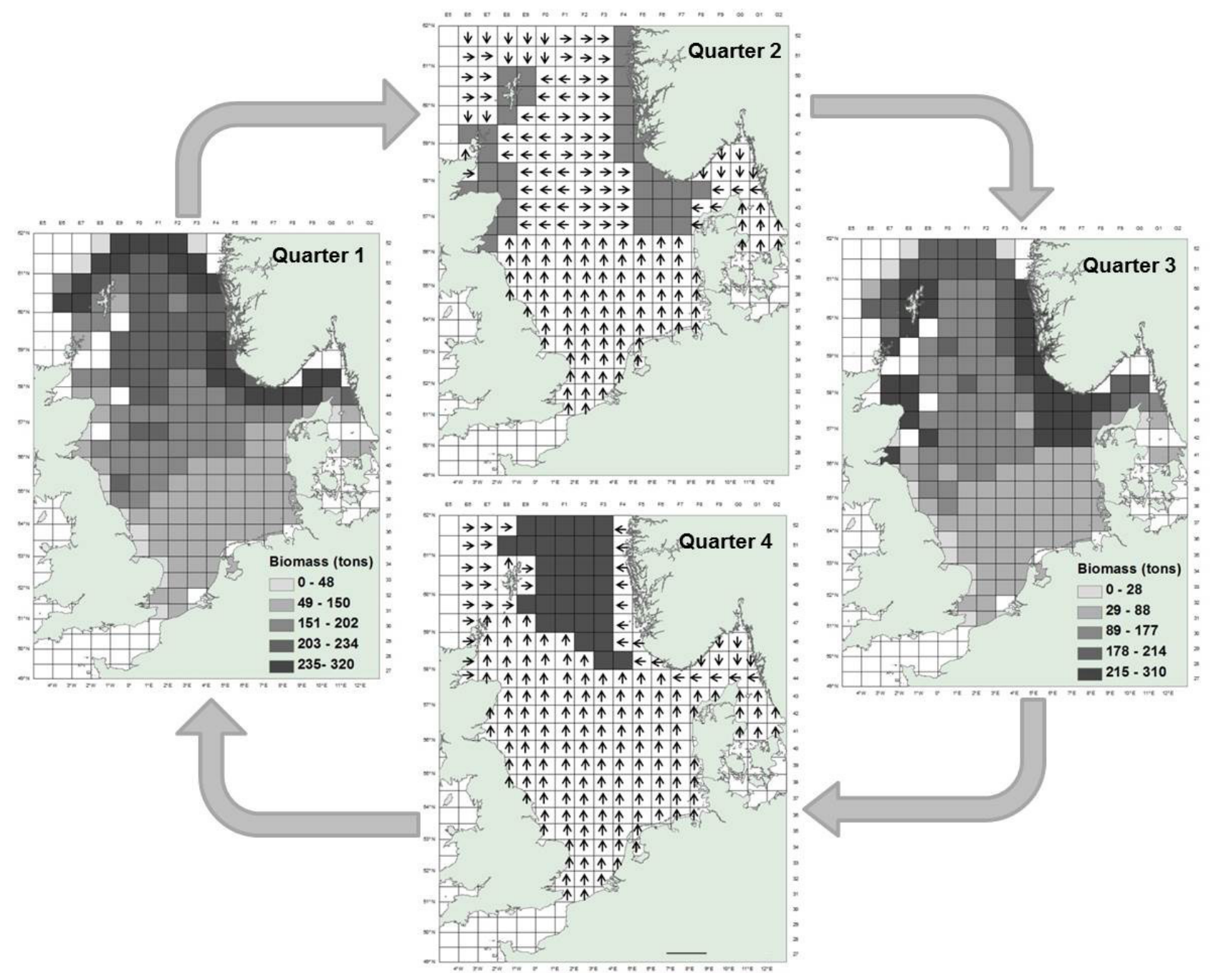

Fig. 2. For quarter 1 and 3, the biomass distribution in tons of North Sea saithe derived from IBTS survey data is shown indicating the distribution during spawning and feeding, respectively. For quarter 2 and 4, no survey data exist and maps show regions that indicate target feeding and spawning grounds, respectively. Arrows indicate the preferred movement of individuals.

\subsubsection{Spatial contraction}

According to the observations made by Casini et al. (2005), the stock in the model contracted or expanded spatially in response to a decrease or increase in stock size, respectively. In the model spatial contraction or expansion of the stock was linear to an increase or decrease of the stock size. For example, when the stock size decreased by $10 \%$ then the number of ICES rectangles where individuals occurred was also reduced by $10 \%$. Using the same rules as for migrations, individuals were move to the centre of concentration. Depending on the season, the centre of concentration was then either the spawning (first and fourth quarter) or the feeding ground (second and third quarter) (Fig. 2).

\subsection{Model description}

The presented modelling approach is based on FishRent a bio-economic optimisation and simulation model (Salz et al. 2011). It is a dynamic feedback model and is composed of six

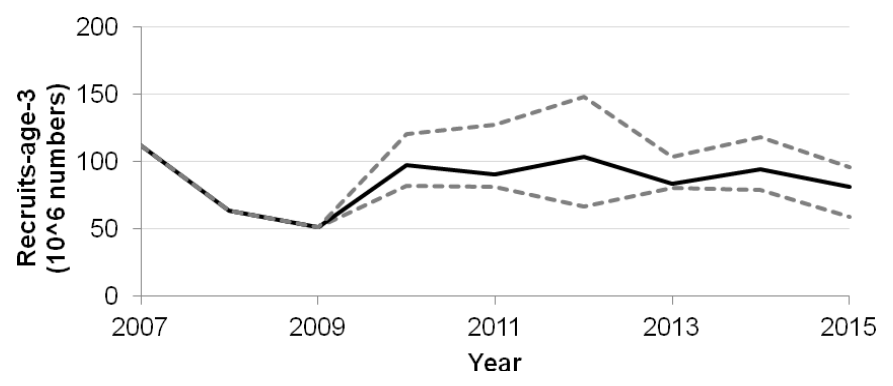

Fig. 3. Predicted number of recruits of age 3 among the modelling period for $S_{\text {diverse }}$. From 2007-2009 observed recruitment values were used. From 2010 onwards median recruitment values (solid lines) with 5 and 95\% intervals (dotted lines) based on 1000 iterations are shown.

sub-modules (Fig. 3). The individual fish growth, fishing and the movement of species is modelled on a monthly time step. The profit maximisation, the aging of fish, the spawning and recruitment event, the calculation of costs and the fleet size 


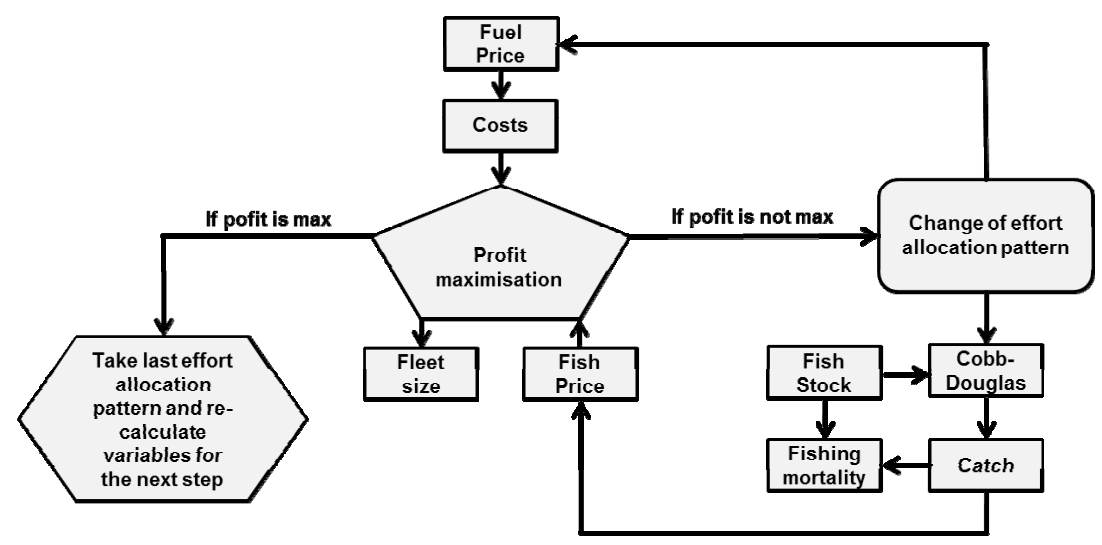

Fig. 4. Conceptual model design with arrows that explain the interaction between the sub-modules. The effort allocation pattern is changed until profit of all fleet segments is maximised. When profit is maximised, the last effort allocation pattern is used in the Cobb-Douglas function to calculate catch, which in turn is used to calculate fishing mortality and SSB for the next step.

adjustment are modelled on an annual time step. It is a model of a fishery system which focuses on the economic drivers, among which the profit earned by the fleet segments is the main driver (Fig. 3). Profit depends on the amount of landed fish, prices for the landed fish, and the costs of fishing. Profit, furthermore, depends on the interest rate for capital invested in the fleet. It is presumed that effort in realistic settings responds to economic incentives. In particular, fleet segments are assumed to seek maximising their profits by setting an optimal level of fishing effort among the ICES Rectangles fished and through the year. This in turn impacts the commercial fish stock. Each year, the applied CONOPT solver (for the detailed description of the CONOPT algorithm, see Drud 1991) uses various levels of fishing effort for each ICES rectangle and for each month within the historical minimum and maximum levels of each fleet segment in the Cobb-Douglas production function and with regard to the cost, revenue and overall profit function (Fig. 3). The solver then selects the effort level for each ICES rectangle, month and fleet segment that results in the maximum overall annual profit of all modelled fleet segments. This optimal effort level used in the Cobb-Douglas production function provides a catch estimate, which is then used in the Pope's approximation to calculate the number of individuals (Fig. 3). In turn, the numbers of individuals are used in the formula that provides an estimate of the instantaneous fishing mortality rate. A Cobb-Douglas production function was chosen as it assumes that fishing mortality is not directly proportional to effort and yield not proportional to stock size. Moreover, it is assumed that fishermen have a perfect knowledge about potential catch rates in each ICES rectangle.

Based on the calculated profits from two years ago, the model determines the level of investment or disinvestment in the fleet (for details see Sect. 3.3.6 and Salz et al. 2011). Any fleet segment that is highly profitable will become bigger and hence the profit of the individual vessels would dissipate in the long-term, given that free access in the fisheries is allowed.

In the model, management constraints activities affect the stock and control the fishery. Simulations of changes in stock biology (e.g., changes in stock productivity), fisheries economics (e.g., changing fuel costs) and/or policy (e.g., alternative management strategies) can be conducted by the model.
A full description of the basic version of the model can be found in (Salz et al. 2011).

\subsubsection{Biological Module}

The Biological Module calculates the population dynamics of the stock. Individual fish grow according to the von Bertalanffy weight-at-age function (von Bertalanffy 1938). For the case study the parameters used in this function were estimated directly from weight-at-age data of the North Sea saithe stock (ICES 2013) (Table S.1). For the years 2007-2009, low recruitment values from the official assessment (ICES 2013) were used (Fig. 4). For the following years recruitment was predicted based on stochastic simulations (Fig. 4). This kind of stochasticity was added to the originally deterministic model, as a failure of recruitment is an important driver of the North Sea saithe fishery. In the model stochastic recruitment (the number of age three fish at the beginning of the year) is calculated once a year via a Beverton and Holt stock-recruitment function (Beverton and Holt 1957), which showed the best fit to stock recruitment data from 1967-2013 (ICES 2013).

$$
R_{t}=\frac{a \times S S B_{t}}{c+S S B_{t}} \times e^{\left(D \times C V-0.5 \times C V^{2}\right)}
$$

with SSB as the overall SSB for saithe at the peak of the spawning period. The parameters $a(a=190.9)$ and $c(c=$ 76.3) are species-specific and were estimated via the nonlinear least-squares approach with data of the North Sea saithe stock (ICES 2013). D is a standard normal deviate and $\mathrm{CV}$ is the coefficient of variation $(\mathrm{CV}=$ standard deviation/mean), estimated based on historical stock sizes at age 3 from 1967-2012 (ICES 2013). Each time the stochastic recruitment model is employed, 1000 stochastic iterations are run. This means that for each time step/year 1000 random iterations from the probability distribution in the stockrecruitment function are run. The number of fish that recruit to each ICES rectangle that are defined as feeding grounds is assumed to be an equal fraction of the entire number of recruits. At the end of each year, all fish of $i$ th age are moved 
to the next age group. All fish older than the maximum age are accumulated in the last age group (plus group at age 10). The catch calculated via a standard Cobb-Douglas production function (see Sect. 3.4.3) is used in the Pope's approximation (Pope 1972) to calculate the number of individuals of $i$ th age at time $t$ :

$$
N_{t, i, k}=N_{t-1, i-1, k} e^{-M_{i}}-\sum_{j}\left(\frac{C_{t-1, i-1, k, j}}{s_{i, k, j}}\right) e^{-\frac{M_{i}}{2}}
$$

where $N_{t, i, k}$ is the number of fish of $i$ th age in $k$ th area at time $t, C_{t, i, k, j}$ is the catch in numbers of $i$ th age, in $k$ th area and $j$ th fleet segment at time $t$ and $s_{i, k, j}$ is the catch share for $i$ th age, in $k$ th area and $j$ th fleet segment (constant over time). The catch share serves to estimate the total catch of a species considering the catches of non-modelled fleet segments (Tables S.1 and S.2). $M_{i}$ is the instantaneous natural mortality rate for $i$ th age (Table S.1). The estimated number of individuals is then used in equation (5) to calculate the age-specific instantaneous fishing mortality

$$
F_{t, i, k}=-\ln \left(\frac{N_{t, i, k}}{N_{t-1, i, k}}\right)-M_{i}
$$

Pope's approximation can be used in the Virtual Population Analysis (VPA) to avoid numerical estimation procedures. Moreover, as long as total mortality is below 1, it has been shown that Pope's approximation works well leading to very small relative errors (Lassen and Medley 2001; MacCall 1986).

\subsubsection{Policy Module}

The Baranov function (Baranov 1918) including the target fishing mortality rate of the management plan is used in the Policy Module to determine the TAC for the next year. In particular, the Baranov model is referred to as a catch model as it provides a catch estimate that is compared with a certain percentage $\left(t s_{t}\right)$ of the TAC from previous year (e.g., $85 \%$ of the TAC, if the TAC change constraint was 15\%) (Table S.1, Eq. (6)). Depending whether this catch estimate is below or above the certain TAC level, the TAC for the following year is decreased (Eq. (6a)) or increased (Eq. (6b)) within the maximum allowed annual change, respectively. If none of the two options is true the TAC for the following year is calculated based on the Baranov catch model alone (Eq. (6c)). The TAC was calculated for the saithe fishery in the North Sea and Skagerrak.

$$
\text { If }
$$

$$
\begin{gathered}
\sum_{i, k}\left[B_{t, i, k} \times \frac{\left(\frac{F_{t, i, k}}{\text { Ftar }_{t-1}}\right) \times \text { Ftar }_{t}}{Z_{t, i, k}} \times\left(1-e^{\left.-Z_{t, i}, k\right)}\right]<\left(1-t s_{t}\right) \times T A C_{t-1}\right. \\
T A C_{t}=\left(1-t s_{t}\right) \times T A C_{t-1}
\end{gathered}
$$

Else if

$$
\begin{gathered}
\sum_{i, k}\left[B_{t, i} \times \frac{\left(\frac{F_{t, i, k}}{\text { Ftar }_{t-1}}\right) \times \text { Ftar }_{t}}{Z_{t, i, k}} \times\left(1-e^{-Z_{t, i, k}}\right)\right]>\left(1-t s_{t}\right) \times T A C_{t-1} \\
T A C_{t}=\left(1+t s_{t}\right) \times T A C_{t-1}
\end{gathered}
$$

Else

$$
T A C_{t}=\sum_{i, k}\left[B_{t, i} \times \frac{\left(\frac{F_{t, i, k}}{\text { Ftar }_{t-1}}\right) \times \text { Ftar }_{t}}{Z_{t, i, k}} \times\left(1-e^{-Z_{t, i, k}}\right)\right]
$$

Where $B_{t, i, k}$ is the biomass of $i$ th age, in $k$ th area and at time $t$ and is the product of number of individuals and mean weightat-age. $Z_{t, i, k}$ is the instantaneous total mortality rate calculated as the sum of instantaneous fishing and natural mortality rate (Table S.1).

\subsubsection{Interface Module}

The Interface Module is linking the modules together. In this module the level of catch and effort is determined, which are subsequently input to the Economic Module and catches are also used as input in the Biological Module. The effort level in terms of fishing days is based on maximising the sum of net profits of the modelled fleet segments with a fixed quota allocation to each fleet segment mimicking the relative stability. The Cobb-Douglas production function is chosen to calculate the catch as it assumes a bi-non-linear relationship between the two inputs, fishing effort and total stock biomass, and the produced catch (Table S.1). In particular, two exponents (alpha and beta) are used as scaling factors for fishing effort and total stock biomass (Table S.1). This is in contrast to the often used assumption that fishing mortality is directly proportional to effort and that yield is proportional to stock size (Eide et al. 2003). It is assumed that modelled fleet segments have a perfect knowledge about potential catch rates. As the catch in the model is estimated from the effort applied in the Cobb-Douglas production function, it is not necessarily equal to the quota. As long as the total catch of a species is less than the quota, the whole catch can be landed. When the total catch exceeds the quota, only the quota is landed, and the catch above the quota is discarded.

\subsubsection{Price Module}

Technically fish prices per age are included in the model but no further investigation was performed as saithe fish prices do not significantly vary between age groups (Table S.2). In the model fuel prices are fixed over time and were set at 0.423 euro $\mathrm{L}^{-1}$, which is the average fuel price of the modelled fleet segments among 2005-2007 (Anderson and Guillen 2009).

\subsubsection{Economy Module}

In the Economic Module gross revenues for each fleet segment are calculated considering the landings value of the modelled species and also the landings value that comes from catches of other not explicitly modelled species (Eq. (A.1), Tables S.1 and S.3). Landings are the difference between catch and discard, whereas discard consists of over-quota catch and catch of undersized species (defined as a fixed proportion of the total catch). Net profit of a fleet segment is calculated as the gross revenue minus all costs (fuel costs, variable costs, 
crew costs, capital costs and fixed costs). The total net profit of all fleet segments is then maximised as described in Section 3.3. In the model fixed and variable costs are considered. Fixed costs include vessels costs such as administrative costs, insurance and maintenance costs. In the model fixed costs are supposed to depend proportionally on fleet capacity that is expressed in terms of number of vessels, while variable costs dynamic is assumed to vary proportionally with fishing effort. Modelled fuel costs vary directly with effort (Eq. (A.2), Table S.1). Capital costs involving depreciation and interest payments are defined in the model as a fixed share of the number of vessels (Tables S.1 and S.3). In the North Sea saithe fishery crew costs are determined as a percentage of the difference between revenues and fuel costs. In the model crew costs are calculated in the same way (Table S.1).

\subsubsection{Behaviour Module}

The economic response of the fleet is modelled through a dynamic investment and disinvestment function (number of vessels), which evaluates the change in the fleet capacity given the economic outcome of the fishery two years ago (Eq. (7)). In reality, the investment/disinvestment function is based on future expectation, but because of the lack of information, past evidence in terms of profitability is used in the model. Thereby the break-even-revenue $\left(B E R_{t, j}\right)$ is an important variable (Eq. (A.3)). It considers revenues and costs with salary to the skipper/owner of the vessel included in the crew costs, and provides the value of gross revenue, where net profit is zero. It is assumed that the fleet changes, i.e., investment and disinvestment take place, proportionately to the relation between the break-even-revenues and the realised revenues. In particular, at the end of each year the number of vessels $\left(F L E_{t, j}\right)$ in $j$ th fleet segment is adjusted in terms of exit (Eq. (7a)) or entry (Eq. (7b)) of vessels depending whether gross revenues $\left(R_{t, j}\right)$ pass below (unprofitable fishery) or exceed (profitable fishery) break-even-revenues two years before, respectively.

This leads in some years to quite substantial changes in the number of vessels in a fleet segment, which could occur as vessels from other fleet segments may enter the fishery. However, it is recognised that the inertia of the system (e.g., licensing, knowledge of skippers) does not allow such full flexibility. Consequently, parameters have been introduced to limit the fluctuation in investment and disinvestment (change in the number of vessels). In particular, a maximum percentage of $10 \%$ in disinvestment $\left(d_{j}^{\max }\right)$ and a maximum change of $5 \%$ in investment $\left(i_{j}^{\max }\right)$ is applied (Eq. (7)). As these two limits are different, it creates and asymmetric investment and disinvestment behaviour. To avoid a continuous growth of fleet size while vessels in the fleet segments have a low activity, the days-at-sea of a fleet segment $\left(D A S_{t, j}\right)$ have to achieve a certain minimum level of days-at-sea per vessel ( das $\left._{j}^{\mathrm{min}}\right)$ before they can be expanded (Eq. (7a), Table S.3). This minimum level is based on the historical average level of days-at-sea for the modelled fleet segments (Table S.1).

$$
\begin{aligned}
& \text { If } B E R_{t, j}>R_{t-1, j} \text { or } D A S_{t-1, j}<d a s_{j}^{\min } \\
& \qquad \operatorname{Inv}_{t, j}=\operatorname{MAX}\left[\begin{array}{l}
d_{j}^{\max } \times F L E_{t-1, j}, \\
\frac{R_{t-1, j}-B E R_{t, j}}{R_{t-1, j}} \times F L E_{t-1, j}
\end{array}\right]
\end{aligned}
$$

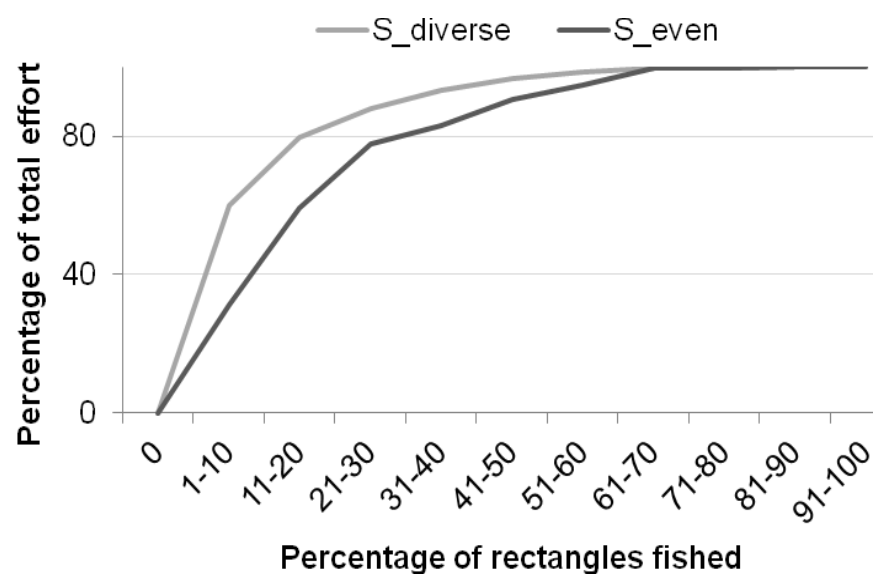

Fig. 5. Cumulative effort versus cumulative area fished (both expressed as a percentage of the respective annual totals) for the modelled fleet segments during the modelling period, after ordering the ICES rectangles fished by decreasing effort.

$$
\begin{aligned}
& \text { If } B E R_{t, j} \leqslant R_{t-1, j} \\
& \qquad \operatorname{Inv}_{t, j}=\operatorname{MIN}\left[\begin{array}{l}
i_{j}^{\max } \times F L E_{t-1, j}, \\
\frac{R_{t-1, j}-B E R_{t, j}}{R_{t-1, j}} \times F L E_{t-1, j}
\end{array}\right]
\end{aligned}
$$

where $I n v_{t, j}$ is the number of vessels that is entering (Eq. (7a)) or leaving (Eq. (7b)) the fleet/fishery.

\section{Simulation results}

\subsection{Effort aggregation}

In the model the solver finds the optimal level of fishing effort as well as its optimal spatio-temporal distribution that maximises the overall net profit. To investigate the impact of simulated species seasonal movements and of modelled economic forces on the spatial distribution of fishing effort, ICES rectangles fished each year were ordered by the amount of predicted fishing effort (days-at-sea), and the cumulative percentage of the total annual effort expended in each of the rectangles fished each year was then calculated. These results were then averaged over the modelling period between 2007 and 2015, and used to plot the cumulative effort against cumulative area fished (Fig. 5). For $\mathrm{S}_{\text {even }} 80 \%$ of the fishing effort occurred in 21-20 ICES Rectangles (Fig. 5). As profit was maximised, effort aggregated in those areas where the costs of fishing (e.g., fuel cost) were low. In particular, as costs (i.e. fuel costs due to longer distance from port) associated with each area differed between fleet segments, profit rates varied also considerably between fleet segments and areas, resulting in the spatial heterogeneity of fishing effort. On average, $90 \%$ of fishing effort occurred in only $41-50 \%$ of the ICES rectangles fished, with $30 \%$ of the fishing effort in the top $10 \%$ of fished ICES rectangles (Fig. 5). As a perfect knowledge about potential catch rates in each ICES rectangle was assumed, effort for $S_{\text {diverse }}$ was even more aggregated with around $90 \%$ of fishing effort occurring in only $21-30 \%$ of the ICES rectangles fished (Fig. 5). 


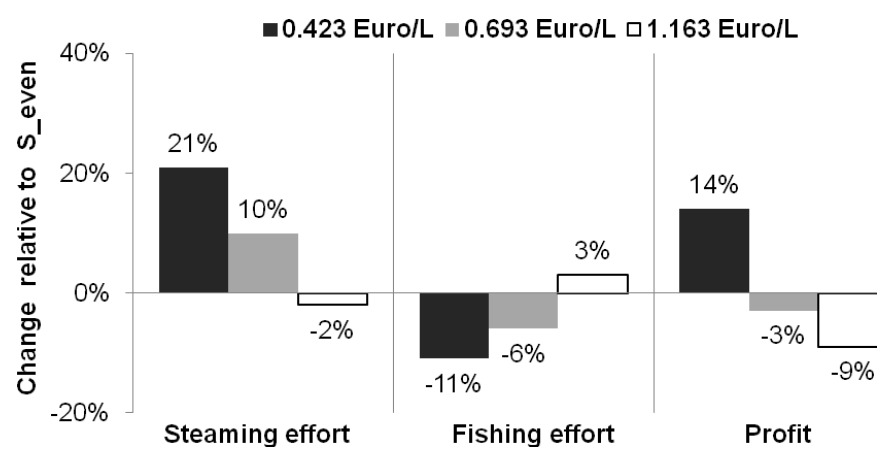

Fig. 6. Change (\%) for the whole modelled fleet in steaming effort (days), fishing effort (days) and profit for $S_{\text {diverse }}$ with 0.423 euro $\mathrm{L}^{-1}$, the fuel price of 2013 without mineral oil tax $\left(0.693\right.$ euro $\left.\mathrm{L}^{-1}\right)$, and the fuel price of 2013 including the mineral oil tax $\left(1.163\right.$ euro $\left.\mathrm{L}^{-1}\right)$, relative to $S_{\text {even }}$.

\subsection{Fuel costs}

For $S_{\text {diverse }}$ the spawning aggregation of saithe in zone 1 during the first quarter of the year accounted for $60 \%$ of the annual effort and $40 \%$ of the annual landings, but was far away from home ports for the majority of the modelled fleet segments. As a result, steaming effort was $10 \%$ higher for $S_{\text {diverse }}$ than the one for $S_{\text {even }}$ (Fig. 6). In turn fishing effort for $S_{\text {diverse }}$ was $12 \%$ lower than the one for $S_{\text {even }}$. Profits for $S_{\text {diverse }}$ were $5 \%$ lower than those for $\mathrm{S}_{\text {even }}$ (Fig. 6).

In Europe fisher are exempt from the mineral oil taxation. To analyse the impact of fuel subsidies on the fishing behaviour the model was run using the baseline value of fuel price of 0.423 euro $\mathrm{L}^{-1}$ and two real fuel price values from 2013: a fuel price of 0.693 euro $\mathrm{L}^{-1}$ (without the mineral oil tax), and a fuel price of 1.163 euro $\mathrm{L}^{-1}$ (including the mineral oil tax) (Federal Ministry of Finance 2009; Federal Statistical Office 2013). When using the low baseline fuel price of 0.423 euro $\mathrm{L}^{-1}$, mainly the French fleet segment increased its effort at the spawning ground by around $18 \%$. As this fleet segment had the longest distance between home port and spawning ground, the total steaming effort was $11 \%$ higher than under a fuel price of 0.693 euro $\mathrm{L}^{-1}$ (Fig. 6). Due to modelled low fuel costs and the fact that the spawning ground was a fishing ground with a high CPUE, the sum of net profits from all modelled fleet segments was $17 \%$ higher for a fuel price of 0.423 euro $\mathrm{L}^{-1}$ than the one for a fuel price of 0.693 euro $\mathrm{L}^{-1}$ (Fig. 6). In contrast, simulating high fuel costs caused a strong reduction of steaming effort and fleet segments tended to fish even closer to their home ports than for $\mathrm{S}_{\text {even }}$, resulting in a $2 \%$ lower steaming effort and 9\% lower net profit for the whole fleet than the ones for $S_{\text {even }}$ (Fig. 6).

Through the year the migratory pattern of saithe resulted in varying patterns of effort (Fig. 7). Although effort tended to concentrate where fish were concentrated, distance from port also affected the distribution of effort. In particular, areas and months with high CPUE values were not always correlated with high levels of effort (Fig. 7).

\subsection{Stock development and catch rates}

From 2007-2009 observed low values of recruitment were used. After this period stochastic simulations based on a
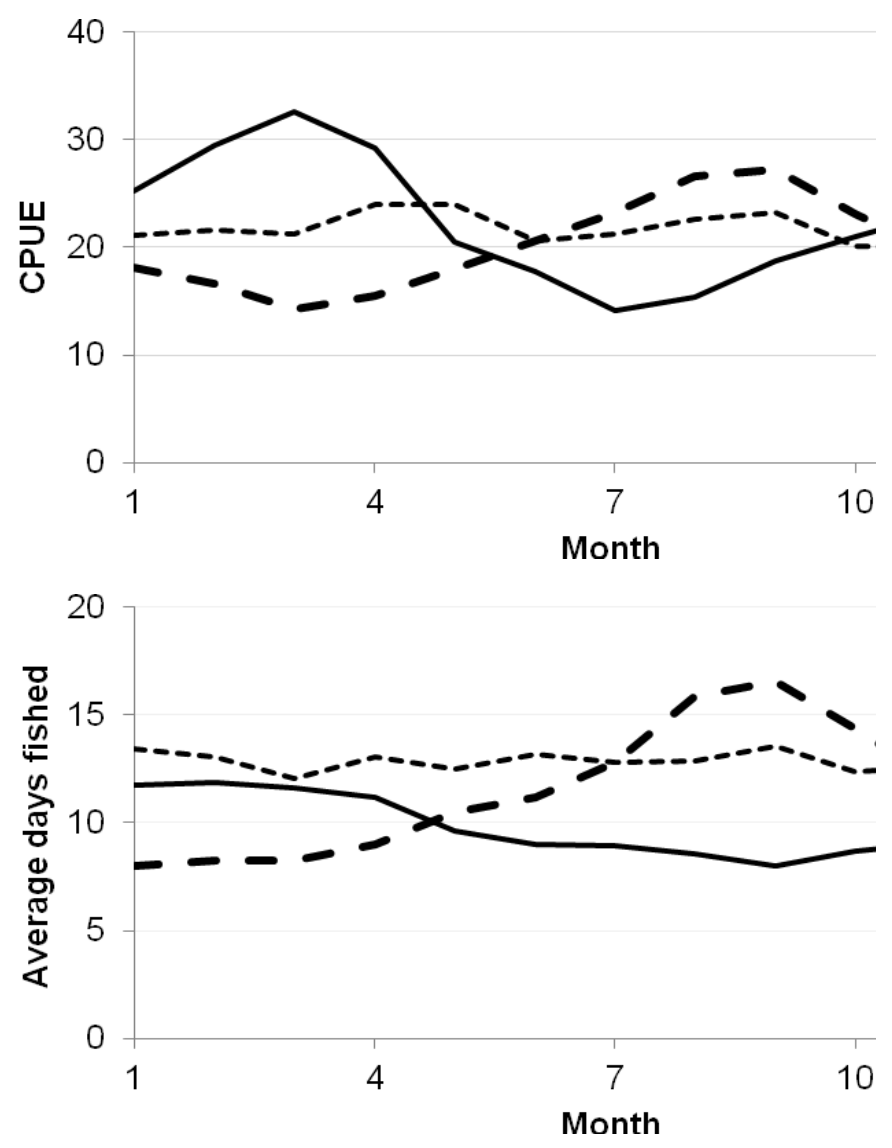

Fig. 7. Variation of CPUE and effort in zone 1-3 among months. Thin solid line: zone 1; dashed line: zone 2; thick solid line: zone 3 .

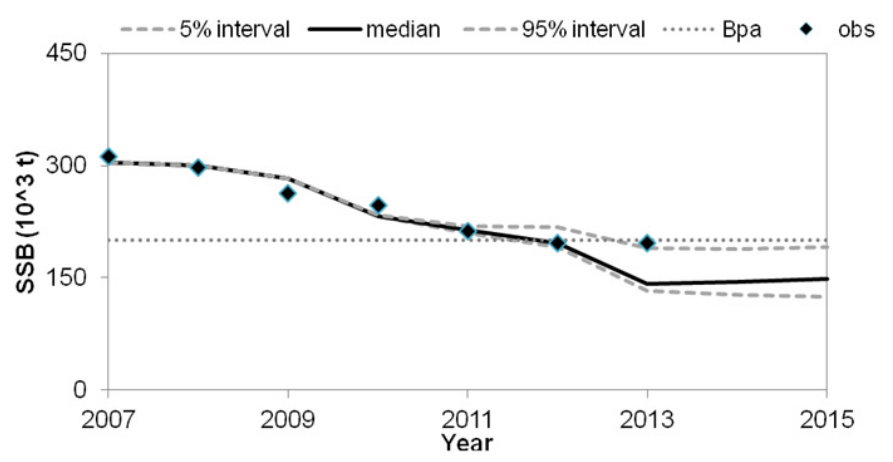

Fig. 8. Median values of spawning stock biomass (SSB) estimates with $5 \%$ and $95 \%$ intervals (dotted lines) for $\mathrm{S}_{\text {diverse }}$ among the modelling period and observed values of SSB (black dots) from 20072013.

Beverton and Holt stock-recruitment relationship were applied. As a result SSB started to decline when the forced low number of recruits of age three reached older age groups in subsequent years (Fig. 8).

With declining stock biomass the stock started to contract spatially, and in relation the density of the stock at the spawning and feeding grounds increased. As it was assumed that fleet segments have a perfect knowledge about the spatial pattern of the stock, fleet segments in $S_{\text {diverse }}$ were locating the seasonal abundance concentrations and obtained high catch rates even 


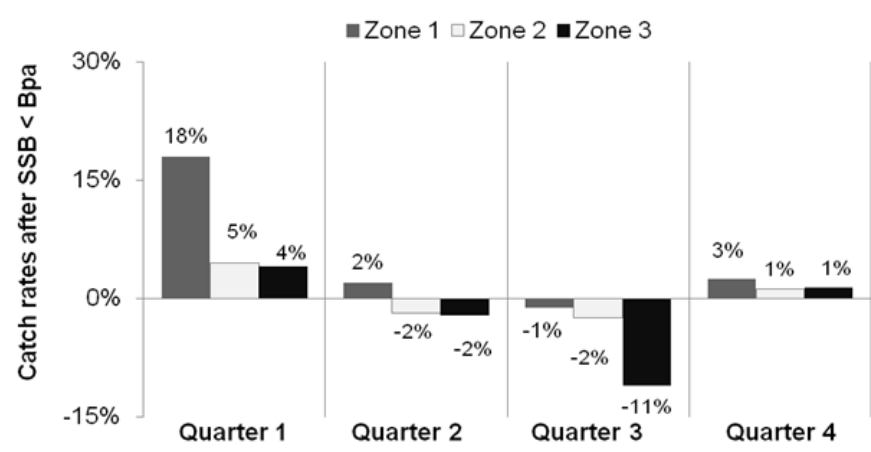

Fig. 9. Change (\%) of median catch rates of 2013-2015 for $S_{\text {diverse }}$ in zones 1-3 relative to median catch rates of 2007-2012 when SSB was above $B_{\mathrm{pa}}$. Diagrams show percentage change values averaged over the modelling years 2007-2012 and 2013-2015, respectively.

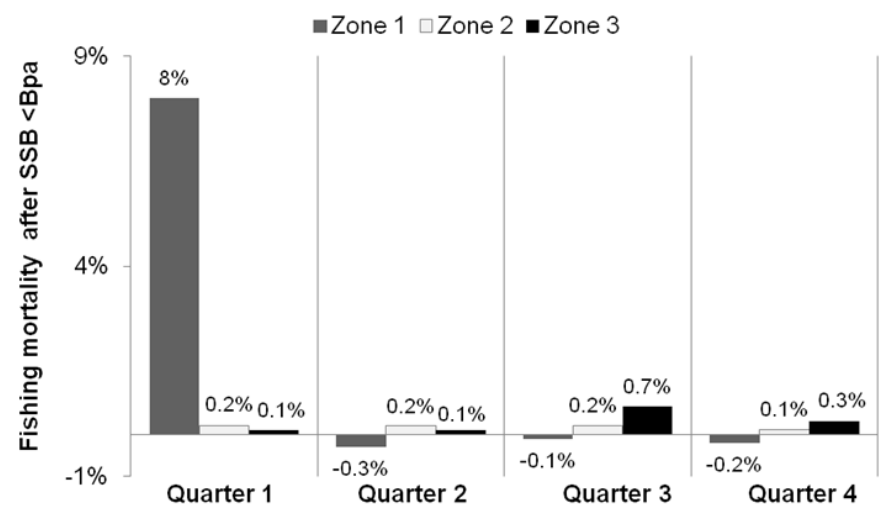

Fig. 10. Change (\%) of average fishing mortality for age groups three to six for $S_{\text {diverse }}$ in zone 1-3 from 2013-2015 relative to fishing mortality rates from 2009-2012 when SSB was above $B_{\mathrm{pa}}\left(B_{\mathrm{pa}}\right.$ is the precautionary reference point for SSB).

at low stock levels (Figs. 8 and 9). When SSB dropped below $B_{\mathrm{pa}}$ in 2012, the density of the stock in zone 1 was increased by $39 \%$ and catch rates for $S_{\text {diverse }}$ in zone 1 (spawning ground) remained higher than those of zone 2 and 3 (feeding grounds) (Figs. 8 and 9). Catch rates in zone 1 even increased by $18 \%$ in the first quarter (Fig. 9). The steaming costs to zone 1, which was further apart from port for all fleet segments, limited the concentration of effort there during the first quarter of the year when SSB was below $B_{\mathrm{pa}}$. In particular, $30 \%$ of the French, $15 \%$ of the English, $10 \%$ of the Danish and $5 \%$ of the German initial effort in zone 1 was shifted to zone 3 after SSB dropped below $B_{\mathrm{pa}}$. Zone 3 absorbed the displaced effort from zone 1 , but as the population density was lower in zone 3 than in zone 1, CPUE declined by $11 \%$ (Fig. 9).

Fishing mortality for North Sea saithe rose by $8 \%$ in zone 1 in quarter 1 , because the average catch per unit of effort increased in this zone (Figs. 7 and 10). Fishing mortalities in the other zones in quarters 2-4, were not significantly affected by the effort shift from zone 1 to 3 , but tended to rather increase than decrease (Fig. 10). For $S_{\text {diverse }}$ the total effort of the combined fleet segments decreased due to a decrease of the quota, but the volume of catches remained relatively stable due to the increased fishing efficiency. More importantly, the initial quota used was already around $20 \%$ higher than the total
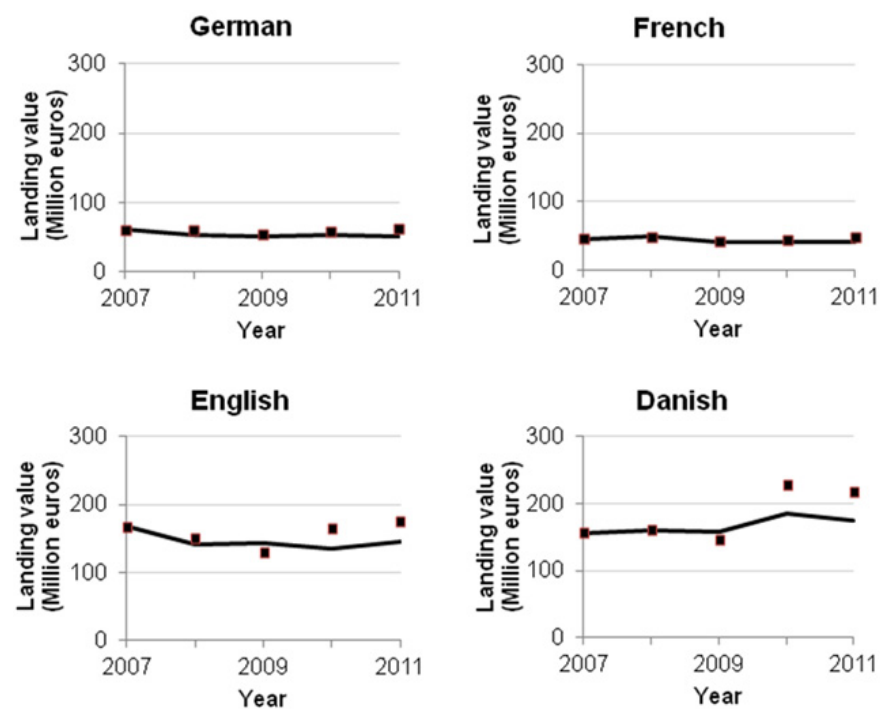

Fig. 11. Predicted (black line) and observed (black squares) landing values are shown for German (a), French (b), English (c) and Danish (d) demersal trawlers and seiners for 2007-2011.

landings (ICES 2013). Thus, although the quota was reduced in the simulations, it was still $6 \%$ higher than the total landings. As a result the overall fishing mortality increased, and the stock remained below $B_{\text {pa }}$ until 2015 (Fig. 8).

\subsection{Sensitivity}

The percentage deviations of profit and SSB from basecase values to values of $S_{\text {even }}$ and $S_{\text {diverse }}$ of profits and SSB by varying parameters were evaluated. One step was to set the dispersal rate of individuals to adjacent areas to 0.1 or 1 , indicating that $10 \%$ or $100 \%$ of the individuals in an ICES rectangle moved to adjacent rectangles, respectively. When using these dispersal rates for $\mathrm{S}_{\text {diverse }}$, estimates of SSB and profits were not considerably different from the basecase values (Table 1). The model was highly sensitive towards the effort and biomass scaling factors (Table 1). Especially when those were set to 0.1 , then profits for $S_{\text {even }}$ were $21 \%$ to $46 \%$ lower than the basecase values and SSB estimates were $80 \%$ higher (Table 1). To test the robustness of the model, simulation results were compared to observed values (Figs. 8 and 11). For the years 2007-2013 predicted SSB estimates were close to observed SSB values (Fig. 8). Although modelled fleet segments were heterogeneous in terms of their economic performance, predicted landings values were close to observed values for the individual fleet segments for 2007-2011, indicating that the model is able to mimic the actual economic situation of individual fleet segments. More importantly, the use of historical data rather than more recent data may not bias the outcome as observed changes among the years were negligible (Fig. 11).

\section{Discussion}

\subsection{Seasonal migrations}

Simulation results have shown that the seasonal movements of North Sea saithe have important implications for the 
Table 1. Results of the sensitivity analysis, shown as deviations (\%) from basecase values of SSB and profit for the modelled fleet segment from different countries. Positive percentages mean that the value when varying the parameter is higher than the base case value, and vice versa.

\begin{tabular}{cccccccc}
\hline Parameter & Values & Scenario & SSB & Danish & English & French & German \\
\hline \multirow{3}{*}{ Dispersal rate } & 0.1 & $\mathrm{~S}_{\text {even }}$ & - & - & - & - & - \\
& 0.1 & $\mathrm{~S}_{\text {diverse }}$ & -5 & 3 & 1 & 2 & 3 \\
\cline { 2 - 8 } & 1 & $\mathrm{~S}_{\text {even }}$ & - & - & - & - & - \\
& 1 & $\mathrm{~S}_{\text {diverse }}$ & 7 & 3 & 1 & 1 & 3 \\
\hline \multirow{3}{*}{ Effort scaling factor alpha } & 0.1 & $\mathrm{~S}_{\text {even }}$ & 80 & -30 & -21 & -45 & -46 \\
& 0.1 & $\mathrm{~S}_{\text {diverse }}$ & 83 & -41 & -26 & -50 & -53 \\
\cline { 2 - 8 } & 1 & $\mathrm{~S}_{\text {even }}$ & -18 & 12 & 16 & 24 & 27 \\
\hline \multirow{3}{*}{ Biomass scaling factor beta } & 1 & $\mathrm{~S}_{\text {diverse }}$ & -12 & 10 & 14 & 19 & 16 \\
\cline { 2 - 8 } & 0.1 & $\mathrm{~S}_{\text {even }}$ & 83 & -75 & -85 & -89 & -82 \\
& 0.1 & $\mathrm{~S}_{\text {diverse }}$ & -16 & -52 & -64 & -68 & -69 \\
\hline & 1 & $\mathrm{~S}_{\text {even }}$ & 12 & 16 & 9 & 14 & 15 \\
& 1 & $\mathrm{~S}_{\text {diverse }}$ & -6 & 9 & 7 & 13 & 11 \\
\hline
\end{tabular}

spatial and seasonal distribution of fishing effort. Given the results of $\mathrm{S}_{\text {diverse }}$, where the fish population was distributed with variable densities across its stock range, the spatial distribution of fishing effort was consequently also highly variable between quarters, years and ICES rectangles. For $\mathrm{S}_{\text {diverse }}$ effort was aggregated, mainly, in the first and third quarter of the year when fish was concentrated on spawning and feeding grounds, respectively. Such movements in response to local changes in abundance have been documented also for other fisheries (Hilborn and Ledbetter 1979; Eales and Wilen 1986).

One underlying assumption of the model is that potential catch rates are perfectly known for each ICES rectangle. However, this assumption might be acceptable as the efficiency of fleets to find the fish stocks and to reach rapidly the abundant fishing areas has highly increased over the last decades (Gascuel et al. 1993; Marchal et al. 2007). As still a substantial amount of steaming time is needed to scan a larger area, it is likely that the model underestimates the steaming costs. Nevertheless, information transfer allows fishermen to reduce the time they spend searching for aggregations. Information transfer is widespread but varies greatly depending on the size of the fishing community, relatedness of participants, differences in ethnicity, and the biology of the species involved (sedentary or mobile) (Branch et al. 2006). In Germany most of the fishermen operating in the North Sea saithe fishery are working for the same company. In this case it is likely that they share actively the information. However, typically active information sharing occurs only between close relatives and long-standing friends, such as that observed in the Marine lobster fishery (Palmer 1991) and the southerneastern Alaskan salmon purseseine fishery (Gatewood 1984). Moreover, the German fishermen fishing for saithe have on average more than 30 years of experience in that fishery. Thus, they might know when and where it is best to fish. Especially the patterns of seasonal migrations might allow fishermen to "predict" catch rates of target species based on the time-of-year (Poos and Rijnsdorp 2007). The predictability of the spatial and temporal patterns of fish stocks has important implications for the spatial distribution of fleet segments, the fishing effort and hence the fishing mortality. However, the migration pattern of species can vary annually. For example, there is evidence that mature saithe skip spawning in certain years and do not migrate (Jorgensen et al. 2006).
In the model, the migration pattern did not change annually. It may hence be an oversimplification. However, simulation results showed that fleet segments followed the seasonal migration pattern of North Sea saithe and especially when SSB dropped below $B_{\mathrm{pa}}$ and the stock contracted at the spawning ground, fishing effort increased proportionally and resulted in an $8 \%$ increase of fishing mortality at this location. The change in fishing effort distribution in relation to species seasonal migrations is also observed in the real saithe fishery. For instance, saithe is heavily exploited by large trawlers along the continental shelf from January to April, where the mature adults congregate to spawn (ICES 2013).

\subsection{Economic pressures}

Based on simulation results effort tended to concentrate where fish abundance was high and/or fishing costs low. This is also supported by Botsford et al. (2009), who suggest that fishing effort may reflect the spatial distribution of the fish population, but also regulatory and economic constraints. The results of $S_{\text {even }}$, show that although the stock was distributed homogeneously, a spatial heterogeneity of fishing effort was observed with effort aggregating in those areas where the costs of fishing (e.g., fuel cost) were low. This is supported by Sampson (1990) and Caddy and Carocci (1999) who demonstrated that spatial allocation of effort is often related to distance from home ports. In the model, distance from ports became more important when SSB dropped below $B_{\mathrm{pa}}$ or when fuel costs were doubled. The long steaming time to zone 1, which was further apart from ports for all modelled fleet segments, limited the concentration of effort there during the first quarter of the year despite the fact that the CPUE was considerably higher in zone 1 due to the spawning aggregation than in zone 3. This highlights the importance of fuel costs and the potential risks of an unsustainable fishery when fuel subsidies are paid, because they encourage the maintenance of fishing effort even when stock levels decline (Sumaila et al. 2006; Tidd et al. 2011).

In the model fleet segments are assumed to respond to profits of the whole fishery. Modelled species profitability, catch rates, quota limits and fishing costs influence the overall profit and the level of fishing effort as well as its spatio-temporal 
distribution. Similarly, the same factors plus the relative desirability of specific fishing locations were identified by other studies to drive changes in fishing effort distribution (e.g., Hilborn and Ledbetter 1979; Gorfine and Dixon 2001; Salas and Gaertner 2004). In the model, effort in areas where costs were high was driven away by lower profits toward high profit areas.

The idea of fishermen responding to economic incentives with effort allocation is controversial, with some authors clearly in favour (Bockstael and Opaluch 1983; Dorn 1998; van Dijk et al. 2014) and others in disagreement (Hanna and Smith 1993; Jacobson and Thomson 1993). For instance, Bockstael and Opaluch (1983) provide empirical documentation, showing that fishermen redistribute their effort in space and time as well as among fisheries in response to changes of expected returns. Lane (1988) applied a partially observable Markov decision process and found that fishermen adjust their effort to gain maximum benefit. Robinson and Pascoe (1998) analysed the validity of the profit maximisation concept as a fisherman's objective when fishing. Their study was based on a broad literature review and empirical studies. They concluded that this concept may be true in some fisheries, like in the one that they studied in the English Channel, but does not completely explain all fishermen behaviour. In addition to profit, other stimuli influence the behaviour such as fuel cost, regulations, the fishermen's abilities, the accessibility of a region or weather condition (Hilborn and Kennedy 1992; Prince and Hilborn 1998; Swain and Wade 2003; Alban et al. 2004; Salas and Gaertner 2004). However, among these factors profit might be the most determining factor. More importantly, the fishing behaviour might be determined as much by economic factors as by biological ones (e.g., changes in fish distribution, stock productivity). The model presented here considers not only the economic factors such as fish prices, fuel prices and costs, but also the biological ones such as changes in recruitment and species seasonal distribution. Moreover, the model has proven to be robust, because projections of SSB and landings values were close to observed values. Therefore, the applied model may provide an integrated understanding about the bio-economic consequences of management measures and about different strategies of fishermen responding to changes in the stock development in terms of low recruitment, species migrations and the contradiction of the stock. For the presented case study such strategies involved the changing in the number of fishing days, the re-allocation of effort in space and time and the switching of vessels to other fisheries.

\subsection{The North Sea saithe stock assessment}

In the North Sea saithe stock assessment catch per unit of effort (CPUE) is used as an index of abundance. More importantly, a proportionality of the abundance index and the stock abundance is assumed. This implies that CPUE is proportional to fish density in the fished areas, and that mean fish density is in the fished areas proportional to stock size. In other words, a proportional change in CPUE is expected to represent the same proportional change in stock size (FAO 1999). However, fish is distributed spatially heterogeneous by given life history processes and heterogeneous environmental conditions (Dieckmann et al. 1999), and the occurrence of detectable patterns in resource availability is a prerequisite for fishermen to optimise their effort allocation in relation to the resource distribution, affecting the relationship between fishing effort and fishing mortality (Trenkel et al. 2013; Paloheimo and Dickie 1964; Hilborn 1985; Hilborn and Walters 1992; Abrahams and Healey 1993; Gillis 2003). The conducted simulations may represent a "worst case" scenario as fishermen have a perfect knowledge about potential catch rates in each ICES rectangle. Thus, high CPUEs were obtained even at low stock levels, undermining the assumption of the proportionality between CPUE and stock size. In this case, CPUEs as a proxy for stock size masked the decline in North Sea saithe abundance. This phenomenon is called hyperstability (Harley et al. 2001). However, although modelled fleet segments were able to locate fish aggregations perfectly, the consequences in terms of fishing mortality were negligible. Nevertheless, there are cases where the consequences of hyperstability can be fatal. One well-known example is the northern Atlantic cod stock collapse off Newfoundland and Labrador (DeYoung and Rose 1993; Rose et al. 1994). This stock became concentrated in an increasingly small area. The fleet followed this tendency and also became concentrated. Just before the collapse of the northern cod stock, the catch rates occurring where cod was concentrated indicated high abundance of the resource (Rose and Kulka 1999).

There are many factors related to aspects of fleet dynamics and fishermen behaviour that can reduce the comparability of CPUE among years and areas and obscure the relationship between CPUE and biomass levels. To detect CPUE signals, it has become common practice in stock assessments to standardise CPUE data to remove trends in vessel characteristics, fishing season, fishing ground, and other factors unrelated to stock abundance (Maunder and Punt 2004). However, Branch et al. (2006) conducted a meta-analysis examining CPUE paired with independent research abundance estimates and demonstrated that even when CPUE series are standardised, in most cases (70\%) there was evidence of hyperstability.

The predicted shift in fishing effort distribution from zone 1 in quarter 1 to zone 3 in quarter 3 was also observed by (ICES 2011). They observed both, the same change in the spatial fishing effort distribution and the same temporal pattern of fishing effort levels of the main commercial fleet segments targeting North Sea saithe (ICES 2011). In particular, they observed that the first quarter of the year, where mainly spawning aggregations are targeted, lost some of its importance it terms of catch volumes, whereas the second and third quarter showed slightly increasing importance (ICES 2011). Moreover, they found that the spatial pattern of the fleet was stable until 2007 with larger concentration of effort in the outflow region of the Skagerrak, along the Norwegian trench and at the northeastern part of the North Sea along the shelf edge (ICES 2011). In recent years, they observed, however, a shift to the outflow region of the Skagerrak, which is further away from the spawning aggregations (Fig. 1). Thus, the simulated changes in the population in terms of seasonal/annual variations in stock distribution and the predicted decline of the stock are in agreement with current observations made by ICES. In the case 
study presented here, this shift in fishing effort did not cause a considerable increase of fishing mortality, but it still indicates its potential impact on the sustainability of a fishery. Thus, the model and its outputs presented here may contribute to the interpretation of catch rates and suggest that hyperstability should be suspected in the North Sea saithe fishery.

\subsection{Fisheries management}

Considering the current long-term management plan for North Sea saithe simulation results predict that SSB will decline faster than estimated by ICES (2013). For the first three modelling years, low values of recruitment that have been observed in the current assessment were used. In particular, recruitment of saithe has fallen below average since 2006 (ICES 2013). In the model, the quota reduction had no effect on catches as they remained relatively stable. The reason for this is that the initial quota has not already been constraining. This mirrors the reality where the TAC was reduced as well and were catches remained also stable until 2010 (ICES 2013). This questions the current management plan and especially its harvest control rule (HCR) for North Sea saithe. Moreover, the fact that CPUE used as a proxy for stock abundance masks the actual decline of SSB and hence involves a high uncertainty. At the moment this high uncertainty is not taken into account by the current management plan for North Sea saithe. Even if future TACs are corrected by making them constraining, they may not be able to account for the spatio-temporal interplay between fleet segments and the stock. In particular, if the saithe stock is spatially contracting at low biomass levels, the model suggests that fishermen will locate these concentrations and fishing efficiency will increase. Moreover, the use of TACs represents a way to control the outputs (e.g., yields) of a fishery but does not allow direct regulation of the level of input (e.g., fishing effort). Thus, a reduction of the TAC without an equivalent reduction in inputs results in an imbalance between harvesting capacity of the fleet and the available catch (Ulrich et al. 2002). An additional management measure that considers the feedback mechanism between fleet segments and the stock and that buffers the uncertainty of CPUEs and the excessive setting of the TAC may be needed to prevent a further decline in SSB. Such a tool could be a temporal area closure to protect SSB and to diverse the fishing effort away from seasonal concentrations of spawning fish, if SSB is falling below a certain threshold (e.g., $B_{\mathrm{pa}}$ ). The model presented here could then be used to investigate the associated costs of various area closures in terms of fishing costs, employment, fleet size reductions and/or effort reductions and benefits such as the level of SSB, fishing mortality and/or higher profits. Furthermore, the model presented here can assess the risk (e.g., the risk of going bankrupt or of a stock collapse) of such a regulation on different fleet segments and the stock.

\section{Conclusion}

Predicting the spatio-temporal effort distribution of heterogeneous fleet segments under varying stock productivity and changing species distribution is clearly a complex manner. Results have shown that average effort rates of different fleet segments and in different areas vary widely in time and in accordance with changes in fuel prices and species spatial distributions. The model presented here can be used to predict the redistribution of fishing effort as conditions and regulations in the fishery change. These predictions may be useful when interpreting CPUEs in stock assessments but also in adjusting policies to accommodate changes in the distribution of effort.

Acknowledgements. The research leading to these results has received funding from the European Community's Seventh Framework Programme (FP7/2007-2013) under grant agreement No. 266445 (VECTORS). Additionally, acknowledgments are given to the projects under grant agreement numbers of 245178 (COEXIST) and 289192 (SOCIOEC) for their financial contribution. Thanks to the numerous researchers of the Data Collection Framework (DCF) the International Council for Exploration of the Sea (ICES) for providing the economic and biological data, respectively.

\section{Appendix}

Gross revenues calculation:

$$
\operatorname{Rev}_{t, j}=\sum_{i}\left(L_{t, i, j} \times p_{i, j}\right) \times\left(1+o_{j}\right)
$$

where $L_{t, i, j}$ are the landings of $i$ th age and $j$ th fleet segment at time $t$, for $p_{i, j}$ and $o_{j}$ (see Table 1).

Fuel cost calculation (see parameter definition and estimation in Table S.1):

$$
F u C_{t, j}=f c_{j} \times D A S_{t, j} \times F P_{j}
$$

Calculation of Break-even-revenue:

$$
B e R_{t-1, j}=\frac{C r C_{t-1, j}+F x C_{t-1, j}+C a C_{t-1, j}}{\left(1-\frac{F u C_{t-1, j}}{\operatorname{Rev} t-1, j}-\frac{V a C_{t-1, j}}{R e v_{t-1, j}}\right)}
$$

where $C r C_{t-1, j}, F x C_{t-1, j}, \quad C a C_{t-1, j}, F u C_{t-1, j}$ and $V a C_{t-1, j}$ are the crew costs, fixed costs, capital costs, fuel costs and variable costs of $j$ th segment for the previous year, respectively.

\section{Supporting Information}

Table S.1. Parameter estimation and data source.

Table S.2. Catch share, catchability and fish prices per age group for all included segments.

Table S.3. Parameter estimates for the economic, behaviour and interface module, see Table S.1, for definitions.

\section{References}

Abrahams M., Healey M., 1993, Some consequences of variation in vessel density: a manipulative field experiment. Fish. Res. 15, 315-322.

Alban F., Le Floc'h P., Boncoeur J., 2004, The impact of economic and regulatory factors on the relative profitability of fishing boats: A case study of the seaweed harvesting fleet of Northwest Brittany (France). Aquat. Living Resour. 17, 185-193. 
Allen P.M., McGlade J.M., 1986, Dynamics of discovery and exploitation - the case of the Scotian Shelf groundfish fisheries. Can. J. Fish. Aquat. Sci. 43, 1187-1200.

Anderson J., Guillen J., 2009, Annual Economic Report on the EU Fishing Fleet. .

Armannsson H., Jonsson S.T., Neilson J.D., Marteinsdottir G., 2007, Distribution and migration of saithe (Pollachius virens) around Iceland inferred from mark-recapture studies. ICES J. Mar. Sci. 64, 1006-1016.

Baranov F.I., 1918, On the question of the biological basis of fisheries. Nauchnge Issledovaniya Ikhtiol. Inst. Izvestiya 1, 81-128.

Béné C., Doyen L., Gabay D., 2001, A viability analysis for a bioeconomic model. Ecol. Econ. 36, 385-396.

Bertelsen E., 1942, Contributions to the biology of the coalfish (Gadus virens L.) in Faroe waters, with special regard to the youngest age groups. Medd. Komm. Danm. Fiskeri og Havunders $11,1-69$.

Beverton R.J.H., Holt S.J., 1957, On the dynamics of exploited fish populations. Fish. Invest. Lond., Ser. 2, 19-533.

Bockstael N.E., Opaluch J.J., 1983, Discrete modelling of supply response under uncertainty: the case of the fishery. J. Environ. Econ. Manage. 10, 125-137.

Booth A.J., 2000, Incorporating the spatial component of fisheries data into stock assessment models. ICES J. Mar. Sci. 57, $858-865$

Botsford L.W., Brumbaugh D.R., Grimes C., Kellner J.B., Largier J. O'Farrell M.R., Ralston S., Soulanille E., Wespestad V., 2009, Connectivity, sustainability, and yield: bridging the gap between conventional fisheries management and marine protected areas. Rev. Fish. Biol. Fish. 19, 69-95.

Branch T.A., Hilborn R., et al., 2006, Fleet dynamics and fishermen behavior: lessons for fisheries managers. Can J. Fish. Aquat. Sci. 63, 1647-1668

Caddy J., Carocci F., 1999, The spatial allocation of fishing intensity by port-based inshore fleets: a GIS application. ICES J. Mar. Sci. $56,388-403$

Cambiè G., Ourens R., Vidal D.F., Carabel S., Freire J., 2012, Economic performance of coastal fisheries in Galicia (NW Spain): case study of the Cíes Islands. Aquat. Living Resour. 25, 195-204

Casini M., Cardinale M., Hjelm J., Vitale F., 2005, Trends in CPUE and related changes in spatial distribution of demersal fish species in the Kattegat and Skagerrak, eastern North Sea, between 1981 and 2003. ICES J. Mar. Sci. 62, 671-682.

Cheung W.W.L., Dunne J., Sarmiento J.L., Pauly D., 2011, Integrating ecophysiology and plankton dynamics into projected maximum fisheries catch potential under climate change in the Northeast Atlantic. ICES J. Mar. Sci. 68, 1008-1018.

Clay D., Stobo W.T., Beck B., Hurley P.C.F., 1989, Growth of juvenile pollock (Pollachius virens L.) along the Atlantic coast of Canada with inferences of inshore-offshore movements. J. Northwest Atl. Fish. Sci. 9, 37-43.

Commission Decision, 2009, Adopting a multiannual Community programme for the collection, management and use of data in the fisheries sector for the period 2011-2013. Off. J. Eur. Union 2010/93/EU.

DeYoung B., Rose G.A., 1993, On recruitment and distribution of Atlantic cod (Gadus morhua) off Newfoundland. Can. J. Fish. Aquat. Sci. 50, 2729-2741.

Dieckmann U., O'Hara B., Weisser W., 1999, The evolutionary ecology of dispersal. Trends Ecol. Evol. 14, 88-90.

Dorn M.W., 1998, Fine-scale fishing strategies of factory trawlers in a midwater trawl fishery for Pacific hake (Merluccius productus). Can. J. Fish. Aquat. Sci. 55, 180-198.
Dornbusch R., Fisher S., 1994, Macroeconomics. McGraw-Hill Inc., Chapter 10.

Drud A., 1991, CONOPT- a large scale GRG codeARKI Consulting Development A.S, Bagsvaerd, Denmark.

Eales J., Wilen J.E., 1986, An examination of fishing location choice in the pink shrimp fishery. Mar Resour. Econ. 2, 331-351.

Eide A., Skjold F., Olsen F., Flaaten O., 2003, Harvest functions: The Norwegian bottom trawl cod fisheries. Mar. Resour. Econ. 18, 81-94.

FAO, 1999, Yearbook of Fishery Statistics. .

Federal Ministry of Finance, 2009, Entwicklung der Energie- (vormals Mineralöl-) und Stromsteuersätze in der Bundesrepublik Deutschland, Bonn.

Federal Office for Agriculture and Food, 2005, 2006, 2007, Bericht über die Fischerei und die Marktsituation für Fischereierzeugnisse in der Bundesrepublik Deutschland. Monatsberichte

Federal Statistical Office, 2013, Erzeugerpreise gewerblicher Produkte (Inlandsabsatz). Preise für leichtes Heizöl, schweres Heizöl, Motorenbenzin und Dieselkraftstoff. Lange Reihen ab 1976 bis August 2013. Artikelnummer: 5612402131085 .

Frost H., Andersen J.L., Hoff A., Thorgersen T., 2009, The EIAA Model: Methodology, definitions and model outline. Copenhagen, Institute of Food and Resource Economics. FOI Report No. 200.

Gascuel D., Fonteneau A., Foucher E., 1993, Analysis of fishing power evolution using virtual population analysis: the case of purse seiners exploiting yellowfin (Thunnus albacares) in the Eastern Atlantic. Aquat. Living Resour. 6, 15-30.

Gatewood J.B., 1984, cooperation, competition, and synergy: information-sharing groups among Southeast Alaskan salmon seiners. Am. Ethnol. 11, 350-370.

Gillis D.M., 2003, Ideal free distributions in fleet dynamics: a behavioral perspective on vessel movement in fisheries analysis. Can. J. Zool. 81, 177-187.

Gorfine H.K., Dixon C.D., 2001, Diver behaviour and its influence on assessments of a quota-managed abalone fishery. J. Shellfish Res. 20, 787-794.

Hanna S.S., Smith C.L., 1993, Attitudes of trawl vessel captains about work, resource use, and fishery management. N. Am. J. Fish. Manage. 13, 367-375.

Harley S.J., Myers R.A., Dunn A., 2001, Is catch-per-unit-effort proportional to abundance? Can. J. Fish. Aquat. Sci. 58, 1760-1772.

Hilborn R., 1985, Fleet dynamics and individual variation - why some people catch more fish than others. Can. J. Fish. Aquat. Sci. 42, $2-13$.

Hilborn R., Kennedy R.B., 1992, Spatial pattern in catch rates: a test of economic theory. Bull. Math. Biol. 54, 263-273.

Hilborn R., Ledbetter M., 1979, Analysis of the British-Columbia salmon purse-seine fleet - Dynamics of movement. J. Fish Res. Board Can. 36, 384-391.

Hilborn R., Walters C.J., 1992, Quantitative fisheries stock assessment: Choice, dynamics and uncertainty. Rev. Fish Biol. Fish. 2, $177-178$.

Homrum E.I., Hansen B., Steingrund P., Hatun H., 2012, Growth, maturation, diet and distribution of saithe (Pollachius virens) in Faroese waters (NE Atlantic). Mar. Biol. Res. 8, 246-254.

ICES, 2010, Report of the Working Group on the Assessment of Demersal Stocks in the North Sea and Skagerrak (WGNSSK). ICES Document CM 2010/ACOM, 13.

ICES, 2011, Report of the Working Group on the Assessment of Demersal Stocks in the North Sea and Skagerrak (WGNSSK). ICES Document CM 2011/ACOM, 560. 
ICES, 2012, Report of the Working Group on the Assessment of Demersal Stocks in the North Sea and Skagerrak (WGNSSK). ICES Document CM 2012/ACOM, 13.

ICES, 2013, Report of the Working Group on the Assessment of Demersal Stocks in the North Sea and Skagerrak (WGNSSK). 24-30 April 2013. ICES Document CM 2013/ACOM:13.

Jacobson L.D., Thomson C.J., 1993, Opportunity costs and the decision to fish for northern anchovy. N. Am. J. Fish. Manage. 13, 27-34.

Jones B.W., Jonson J., 1971, Coalfish tagging experiments at Iceland. Rit Fiskideildar 5, 1-27.

Jones M.C., Dye S.R., Fernandes J.A., Froelicher T.L., Pinnegar J.K., Warren R., Cheung W.W.L., 2013, Predicting the impact of climate change on threatened species in UK waters. Plos One 8, e54216.

Jones M.C., Dye S.R., Pinnegar J.K., Warren R., Cheung W.W.L., 2012, Modelling commercial fish distributions: Prediction and assessment using different approaches. Ecol. Model. 225, 133-145.

Kaschner K., Ready J., et al., 2008, AquaMaps: Predicted range maps for aquatic species. World wide web electronic publication, wwwaquamapsorg, Version 10, 2008.

Kerr L.A., Cadrin S.X., Secor D.H., 2010, The role of spatial dynamics in the stability, resilience, and productivity of an estuarine fish population. Ecol. Appl. 20, 497-507.

Lane D.E., 1988, Investment decision making by fishermen. Can. J. Fish. Aquat. Sci. 45, 782-796.

Lassen H., Medley P., 2001, Virtual population analysis: a practical manual for stock assessment. FAO.

Marchal P., Andersen B., Caillart B. Eigaard O., Guyader O., et al., 2007, Impact of technological creep on fishing effort and fishing mortality, for a selection of European fleets. ICES J. Mar. Sci. 64, 192-209.

Maunder M.N., Punt A.E., 2004, Standardizing catch and effort data: a review of recent approaches. Fish. Res. 70, 141-159.

Olsen E., Aanes S., Mehl S., Holst J.C., Aglen A., Gjosaeter H., 2010, Cod, haddock, saithe, herring, and capelin in the Barents Sea and adjacent waters: a review of the biological value of the area. ICES J. Mar. Sci. 67, 87-101.

Opaluch J.J., Bockstael N.E., 1984, Behavioral modeling and fisheries management. Mar. Resour. Econ. 1, 105-115.

Palmer C.T., 1991, Kin-selection, reciprocal altruism, and information sharing among Maine lobstermen. Ethol. Sociobiol. 12, 221-235.

Paloheimo J., Dickie L., 1964, Abundance and fishing success. Rapp. P.-V. Réun. Cons. Internat. Explor. Mer 155.

Pelletier D., Magal P., 1996, Dynamics of a migratory population under different fishing effort allocation schemes in time and space. Can. J. Fish. Aquat. Sci. 53, 1186-1199.

Poos J.J., Rijnsdorp A.D., 2007, An "experiment" on effort allocation of fishing vessels: the role of interference competition and area specialization. Can. J. Fish. Aquat. Sci. 64, 304-313.
Prince J., Hilborn R., 1998, Concentration profiles and invertebrate fisheries management. Can. Spec. Publ. Fish. Aquat. Sci. 187-198.

Reinsch H., 1976, Köhler und Steinköhler. A. Ziemsen Verlag Vittenberg Lutherstadt.

Robinson C., Pascoe S., 1998, Input controls, input substitution and profit maximisation in the English Channel beam trawl fishery. J. Agric. Econ. 49, 16-33.

Rose G.A., Atkinson B.A, Baidr J., Bishop C.A., Kulka D.W., 1994, Changes in distribution of Atlantic cod and thermal variations in Newfoundland waters, 1980-1992. ICES Mar. Sci. Symp. 198, $542-552$.

Rose G.A, Kulka D.W., 1999, Hyperaggregation of fish and fisheries: how catch-per-unit-effort increased as the northern cod (Gadus morhua) declined. Can. J. Fish. Aquat. Sci. 56(S1), 118-127.

Salas S., Gaertner D., 2004, The behavioural dynamics of fishers: management implications. Fish Fish. 5, 153-167.

Salz P., Buisman E., Frost, H., Accadia, P., Prellezo, R., Soma, K., 2011, Fishrent: bio-economic simulation and optimization model for fisheries. LEI Report 2011, n 24.

Sampson D.B., 1990, Fishing Technology and Fleet Dynamics: Predictions from a bio-economic model. Portsmouth Polytechnic, Centre for Marine Resource Economics.

Sumaila U.R., Teh L., Watson R., Tyedmers P., Pauly D., 2008, Fuel price increase, subsidies, overcapacity and resource sustainability. ICES J. Mar. Sci. 65, 832-840.

Swain D.P., Wade E.J., 2003, Spatial distribution of catch and effort in a fishery for snow crab (Chionoecetes opilio): tests of predictions of the ideal free distribution. Can. J. Fish. Aquat. Sci. 60, 897-909.

Tidd A.N., Hutton T., Kell L.T., Padda G., 2011, Exit and entry of fishing vessels: an evaluation of factors affecting investment decisions in the North Sea English beam trawl fleet. ICES J. Mar. Sci. 68, 961-971.

Trenkel V.M., Beecham J.A., Blanchard J.L., Edwards C.T.T., Lorance P., 2013, Testing CPUE-derived spatial occupancy as an indicator for stock abundance: application to deep-sea stocks. Aquat. Living Resour. 26, 319-332.

Ulrich C., Pascoe S., Sparre PJ., De Wilde JW., Marchal P., 2002, Influence of trends in fishing power on bioeconomics in the North Sea flatfish fishery regulated by catches or by effort quotas. Can. J. Fish. Aquat. Sci. 59, 829-843.

van Dijk D., Hendrix E.M., Haijema R., Groeneveld R.A., van Ierland E.C., 2014, On solving a bi-level stochastic dynamic programming model for analyzing fisheries policies: Fishermen behavior and optimal fish quota. Ecol. Model. 272, 68-75.

von Bertalanffy L., 1938, A quantitative theory of organic growth. Hum. Biol. 10, 181-213.

Wilen J.E., 1979, Fisherman behavior and the design of efficient fisheries regulation programs. J. Fish. Board Can. 36, 855-858. 


\section{Supporting Information}

Table S.1. Parameter estimation and data source.

\begin{tabular}{|c|c|c|c|c|}
\hline Parameter & Definition & Value & Estimation & Data source \\
\hline$a$ & $\begin{array}{l}\text { Species-specific Beverton and Holt } \\
\text { parameter }\end{array}$ & 190.90 & $\begin{array}{l}\text { Non-linear least square } \\
\text { approach }\end{array}$ & (ICES 2012) \\
\hline$(\alpha)$ & $\begin{array}{l}\text { Cobb-Douglas production function } \\
\text { coefficients }\end{array}$ & 0.60 & Taken from literature & (Frost et al. 2009) \\
\hline$b$ & $\begin{array}{l}\text { Exponent of the length-weight } \\
\text { relationship }\end{array}$ & 3.00 & $\begin{array}{l}\text { Non-linear least square } \\
\text { approach }\end{array}$ & (ICES 2012) \\
\hline$\beta$ & $\begin{array}{l}\text { Cobb-Douglas production function } \\
\text { coefficients }\end{array}$ & 0.40 & Taken from literature & (Frost et al. 2009) \\
\hline$c$ & $\begin{array}{l}\text { Species-specific Beverton and } \\
\text { Holt parameter }\end{array}$ & 76.38 & $\begin{array}{l}\text { Non-linear least square } \\
\text { approach }\end{array}$ & (ICES 2012) \\
\hline $\operatorname{cas}_{j}$ & Capital cost share for $j$ th segment & See Table S.3 & $\begin{array}{l}\text { Average ratio of capital } \\
\text { costs and fleet size of } \\
2005-2007\end{array}$ & \multirow{7}{*}{ (Anderson and Guillen 2009) } \\
\hline$c s_{j}$ & Crew share for $j$ th segment & See Table S.2 & $\begin{array}{l}\text { Average crew } \\
\text { share of } 2005-2007\end{array}$ & \\
\hline $\operatorname{das}_{j}^{\mathrm{mIn}}$ & $\begin{array}{l}\text { Minimum level of days-at-sea per } \\
\text { vessel }\end{array}$ & See Table S.3 & $\begin{array}{l}\text { Average days-at-sea per } \\
\text { vessel of } 2005-2007\end{array}$ & \\
\hline$d_{j}^{\max }$ & $\begin{array}{l}\text { Maximum percentage in } \\
\text { disinvestment }\end{array}$ & 0.10 & $\begin{array}{l}\text { Based on historical } \\
\text { disinvestments }\end{array}$ & \\
\hline$f c_{j}$ & $\begin{array}{l}\text { Average fuel consumption per unit } \\
\text { of effort for } j \text { th segment }\end{array}$ & See Table S.3 & $\begin{array}{l}\text { Average fuel consumption } \\
\text { per day at sea of } 2005-2007\end{array}$ & \\
\hline$f s_{j}$ & Fixed cost share for $j$ th segment & See Table S.3 & $\begin{array}{l}\text { Average sum of fixed costs } \\
\text { and revenues per vessel for } \\
2005-2007\end{array}$ & \\
\hline$i_{j}^{\max }$ & Maximum change in investment & 0.05 & $\begin{array}{l}\text { Based on historical changes } \\
\text { in investment }\end{array}$ & \\
\hline$k$ & Van Bertalanffy parameter & 0.24 & $\begin{array}{l}\text { Non-linear least square } \\
\text { approach }\end{array}$ & (ICES 2012) \\
\hline$\overline{M_{i}}$ & Instant. natural mortality & 0.20 & Taken form assessment & (ICES 2012) \\
\hline$\overline{o_{j}}$ & $\begin{array}{l}\text { Percentage of landings value } \\
\text { coming from other species }\end{array}$ & See Table S.3 & Taken from report & $\begin{array}{l}\text { (Anderson and Guillen } \\
\text { 2009) }\end{array}$ \\
\hline$p_{i, j}$ & $\begin{array}{l}\text { Kilogram fish price for } i \text { th age and } \\
j \text { th segment }\end{array}$ & See Table S.2 & $\begin{array}{l}\text { German: see source. } \\
\text { Others: Landings value per } \\
\text { landings weight }\end{array}$ & $\begin{array}{l}\text { Federal Office for } \\
\text { Agriculture and Food } \\
2005,2006,2007) \\
\end{array}$ \\
\hline$r$ & Species specific growth parameter & 0.074 & $\begin{array}{l}\text { Non-linear least square } \\
\text { approach }\end{array}$ & (ICES 2012) \\
\hline$s h_{j}$ & $\begin{array}{l}\text { Share of the total catch for } \\
j \text { th segment }\end{array}$ & See Table S.3 & $\begin{array}{l}\text { Average catch share of } \\
\text { modeled segments }\end{array}$ & $\begin{array}{l}\text { (Anderson and Guillen } \\
\text { 2009) }\end{array}$ \\
\hline$s_{i, j}$ & $\begin{array}{l}\text { Catch share of } i \text { th age and } j \text { th } \\
\text { segment }\end{array}$ & See Table S.2 & $\begin{array}{l}\text { Average catch share of } \\
\text { 2005-2007s }\end{array}$ & $\begin{array}{l}\text { (Anderson and Guillen } \\
\text { 2009; ICES 2012) }\end{array}$ \\
\hline$t_{0}$ & $\begin{array}{l}\text { Hypothetical time at which fish } \\
\text { weight was zero }\end{array}$ & -0.133 & $\begin{array}{l}\text { Non-linear least square } \\
\text { approach }\end{array}$ & (ICES 2012) \\
\hline$\overline{t e} e_{j}$ & Technological advancement & $\overline{0.015}$ & Taken form literature & $\begin{array}{l}\text { (Dornbusch and Fisher } \\
\text { 1994) }\end{array}$ \\
\hline$\overline{v s_{j}}$ & $\begin{array}{l}\text { Variable costs share for } j \text { th } \\
\text { segment }\end{array}$ & See Table S.3 & $\begin{array}{l}\text { Average ratio of variable } \\
\text { costs and gross revenues }\end{array}$ & $\begin{array}{l}\text { (Anderson and Guillen } \\
\text { 2009) }\end{array}$ \\
\hline$W_{\infty}$ & $\begin{array}{l}\text { Asymptotic weight }(\mathrm{kg}) \text { at } t \text { equals } \\
\text { infinity }\end{array}$ & 16.6 & $\begin{array}{l}\text { Non-linear least square } \\
\text { approach }\end{array}$ & (ICES 2012) \\
\hline
\end{tabular}


Table S.2. Catch share, catchability and fish prices per age group for all included segments.

\begin{tabular}{|c|c|c|c|c|c|c|c|c|c|c|c|}
\hline Parameter & Segment* & age1 & age2 & age3 & age4 & age5 & age6 & age7 & age8 & age9 & age10 \\
\hline \multirow[t]{6}{*}{ Catch share $\left(s_{i, j}\right)$} & GE dts VL1224 & 0 & 0 & 0.009 & 0.006 & 0.005 & 0.004 & 0.003 & 0.002 & 0.002 & 0.001 \\
\hline & GE dts VL24 & 0 & 0 & 0.226 & 0.153 & 0.145 & 0.103 & 0.084 & 0.063 & 0.051 & 0.034 \\
\hline & DK dts VL0012 & 0 & 0 & 0.005 & 0.004 & 0.005 & 0.005 & 0.004 & 0.003 & 0.002 & 0.001 \\
\hline & DK dts VL1224 & 0 & 0 & 0.027 & 0.018 & 0.017 & 0.012 & 0.010 & 0.007 & 0.006 & 0.004 \\
\hline & FR dts VL40 & 0 & 0 & 0.247 & 0.167 & 0.159 & 0.113 & 0.092 & 0.069 & 0.056 & 0.037 \\
\hline & UK dts_VL24 & 0 & 0 & 0.114 & 0.077 & 0.073 & 0.052 & 0.042 & 0.032 & 0.026 & 0.017 \\
\hline \multicolumn{12}{|c|}{ Catchability coefficient } \\
\hline \multirow[t]{6}{*}{$\left(q_{i, j}\right)$} & GE dts VL1224 & 0 & 0 & 0.073 & 0.053 & 0.092 & 0.050 & 0.038 & 0.034 & 0.014 & 0.005 \\
\hline & GE dts VL24 & 0 & 0 & 0.783 & 0.564 & 0.982 & 0.534 & 0.406 & 0.362 & 0.145 & 0.056 \\
\hline & DK dts VL0012 & 0 & 0 & 0.050 & 0.045 & 0.055 & 0.034 & 0.024 & 0.022 & 0.012 & 0.002 \\
\hline & DK dts VL1224 & 0 & 0 & 0.011 & 0.008 & 0.014 & 0.008 & 0.006 & 0.005 & 0.002 & 0.001 \\
\hline & FR dts VL40 & 0 & 0 & 0.964 & 0.694 & 1.208 & 0.657 & 0.500 & 0.446 & 0.178 & 0.068 \\
\hline & UK dts VL24 & 0 & 0 & 0.095 & 0.068 & 0.119 & 0.065 & 0.049 & 0.044 & 0.018 & 0.007 \\
\hline \multicolumn{12}{|l|}{ Fish prices $\left(p_{i, j}\right)$} \\
\hline & GE dts VL1224 & 0.510 & 0.510 & 0.510 & 0.510 & 0.510 & 0.547 & 0.547 & 0.547 & 0.845 & 0.845 \\
\hline & GE dts VL24 & 0.465 & 0.465 & 0.465 & 0.465 & 0.465 & 0.499 & 0.499 & 0.499 & 0.772 & 0.772 \\
\hline & DK dts VL0012 & 0.561 & 0.561 & 0.561 & 0.561 & 0.561 & 0.602 & 0.602 & 0.602 & 0.931 & 0.931 \\
\hline & DK dts VL1224 & 0.482 & 0.482 & 0.482 & 0.482 & 0.482 & 0.517 & 0.517 & 0.517 & 0.799 & 0.799 \\
\hline & FR dts VL40 & 0.619 & 0.619 & 1.027 & 1.027 & 1.027 & 1.027 & 1.027 & 1.027 & 1.027 & 1.027 \\
\hline & UK dts VL24 & 0.419 & 0.419 & 0.695 & 0.695 & 0.695 & 0.695 & 0.695 & 0.450 & 0.695 & 0.695 \\
\hline
\end{tabular}

$(*)$ GE, DK, FR and UK indicated the nations Germany, Denmark, France and England, respectively; dts was demersal trawlers and/or demersal seiners. The last part indicated the vessel length (VL0012-vessels 0 to $12 \mathrm{~m}$, VL1224-vessels 12 to $24 \mathrm{~m}$, VL24-vessels larger than $24 \mathrm{~m}$ and VL40-vessels larger than $40 \mathrm{~m}$ ).

Table S.3. Parameter estimates for the economic, behaviour and interface module, see Table S.1, for definitions.

\begin{tabular}{lcccccccc}
\hline Segment* & $o$ & $f c$ & $c s$ & $v s$ & $f s$ & $c a s$ & das $^{\min }$ & $s h$ \\
$(\%)$ & $(1000$ L/day $)$ & $(\%)$ & $(\%)$ & $\begin{array}{c}\text { sh } \\
(1000 € / \text { vessel })\end{array}$ & $\begin{array}{c}\text { (1000 } € / \text { vessel }) \\
(\text { days })\end{array}$ \\
\hline GE dts VL1224 & 81 & 161 & 7.7 & 8.7 & 25.826 & 16.129 & 34 & 1.8 \\
GE dts VL24 & 65 & 271 & 4.1 & 6.3 & 37.955 & 61.879 & 91 & 11.9 \\
DK dts VL0012 & 76 & 216 & 5.9 & 6.5 & 13.019 & 9.684 & 61 & 5.8 \\
DK dts VL1224 & 69 & 423 & 5.3 & 12.4 & 43.508 & 34.788 & 125 & 1.3 \\
FR dts VL40 & 89 & 369 & 3.8 & 27.7 & 86.658 & 123.166 & 155 & 13.9 \\
UK dts VL24 & 86 & 437 & 3.6 & 22.7 & 56.961 & 51.767 & 122 & 10.2 \\
\hline
\end{tabular}

$\left({ }^{*}\right)$ GE, DK, FR and UK indicated the nations Germany, Denmark, France and England, respectively; dts was demersal trawlers and/or demersal seiners. The last part indicated the vessel length (VL0012-vessels 0 to $12 \mathrm{~m}$, VL1224-vessels 12 to $24 \mathrm{~m}$, VL24- vessels larger than $24 \mathrm{~m}$ and VL40-vessels larger than $40 \mathrm{~m}$ ). 